\title{
Italian language curriculum versus labour market challenges
}

\author{
Dr. Aida Gjinali \\ University of Tirana \\ Faculty of Foreign Languages \\ Department of Italian language \\ aidagjinali@yahoo.it \\ Dr. Diana Kastrati, \\ University of Tirana \\ Faculty of Foreign Languages \\ Department of Italian language \\ dianakastrati@yahoo.it
}

\section{Doi:10.5901/jesr.2014.v4n2p447}

\begin{abstract}
The purpose of this research is to emphasize the issues that arise from the actual application of Italian language curriculum versus nowadays labour market challenges that are met in Albania and abroad, and to offer possible solutions related to it. In this research we are going to present a summarized overview of the Italian language curriculum for both existing studies' cycles in the Faculty of Foreign Languages, of the development of this language in the Albanian framework, a summarized overview on the Italian or Italian-Albanian enterprises operating in our country and the employment needs they have.It is a well-known fact that the Italian language cannot be considered an instrumental language; therefore, there are encountered difficulties in studying, acknowledging and using it within this framework. From the surveys carried on with first year students in our faculty, there is noticed a lack of motivation from their part in studying Italian, a very significant indicator which emphasizes the difficulties this language faces while functioning as a labour language in a labour market. Of course, this will result in a drastic reduction in the number of students who want to study Italian, and a decrease in the quality of students who will apply in our faculty in the upcoming years. It is true that the average marks of students learning Italian has been that of a decreasing trend. Also, the employment index of graduated students according to the proper study profile is very low, and this highlights the low level of needs and requirements that labour market offers for this students' profile. Therefore, there arises the necessity of an urgent intervention in the curriculum of this language, to offer programmes which are suitable to the education of people who can find a job in their study field in the future. Also, this intervention is necessary not only in the employment framework, but also in handling the challenges that we face due to globalization; in order to make our faculty and especially the programs offered by the Italian department more attractive, so that they can serve to the requirements and needs of the future, in collaboration with local and foreign institutions. The ways and the forms of this intervention and the proposals will be a very important part of this research. This intervention will be vertical, as well as horizontal, for more efficiency and productivity in the education of people capable to manage future challenges.
\end{abstract}

Keywords: curriculum, Italian language, labour market, student

Teaching Italian language at the faculty of Foreign Languages, Tirana, is facing more and more problems that are directly connected to its usage as a language able to be used in practice in the labour market in Albania and abroad. This is greatly noticed in those generations which have finished both study cycles in this faculty and who are now facing difficulties finding a job in their specific profile. Not only this, but the majority of them are either employed with no relation to their studies, or, in the best case, in positions that require knowledge of Italian language, such as call centres, but this does not justify long years of studies, cost, efforts and their education. Without any doubts, this depends on many factors:

First of all, Italian language, different from the English one, is not and cannot be considered an instrumental language, and, as Balboni claims, it is considered a "useless" language (Balboni, E. P. 1994) with regards to its instrumental usage, and can be such only in those cases where it can be applied in countries, where political, economic, social and cultural relations and geographical proximity allows it. In fact, the Albanian environment favours such a thing. The relations 
between Italy and Albania have been and continue to be of mutual collaborative nature, which favours a positive atmosphere with regards to a multitude of relations between them.

As far as the way Italian is taught in Albania is concerned, let's refer to statistics. Teaching Italian in high school or elementary is ranked third, after English and French. Recent statistics (M.A.SH) of 2013 show that the number of pupils who study Italian before going to university, as a first or second language, is 65000 (M.A.SH).

Different projects of the Italian government, which are managed and followed up from Italian institutions present in Albania, such as: Italian Embassy through the Education office, Italian Institute of Culture, etc., try to invest, preserve and spread Italian language and culture in Albania. Therefore, projects such as liria, initiated years ago and which is present in 19 regions of the country (Alla, 2012), not only has assisted this spreading, but has also offered continuous training of Italian language teachers on the recent developments of global glottodidactics, through a close collaboration with famous local and foreign professors. Initiatives, enterprises and different cultural activities that accompany this process are often done from these institutions, in order not to lose what Italian language used to mean to Albanians: the language of music, movies, of love and future. Actually, in some aspects the Italian language has lost ground, although it has gained in other aspects, but despite this, it has suffered continuous downfall. In a country where $60 \%$ of the population understood and 50\% spoke Italian (Italian Embassy, 2014), this number has decreased due to some factors:

1. Italian television is not the only access Albanians have to the rest of the world

2. The need for knowing other languages much more necessary that Italian with regards to studies, employment and emigration, despite the fact that in Italy the presence of regular Albanian immigrants is around 482.627 (ISTAT, 2012) equal to $13,7 \%$ of the number of foreigners living in ltaly, and which ranks it as the second largest foreign community in Italy ( Husha A., 2013). Let's add to this the number of 11.802 Albanian students in Italian universities, ranking them as the first foreign students' community in Italy.

Still, requests to study and use this language for employment purposes are declining. This can be noticed from the decreasing number of students that attend studies in this faculty and the declining quotas offered for studying Italian in the same faculty. This number varies from 80-120 students a year, but the number of those who are registered as final students of this language is always decreasing. There are further drops in the upcoming years due to internal factors, such as:

- Lack of will and lack of motivation to study Italian

- Small knowledge of the perspectives this language has to offer

- Difficulties in deeper studies of this language

- Large number of failed exams

- Other study or employment perspectives

- Dropping the studies with no convincing reason

- External factors

Motivation to learn this language in its entire complexity and using it in the future is low and this is clearly shown in the applications of high school students in the acceptance forms, where they have the right to choose ten study fields and then, based on the gained points, the Ministry of Education defines which field they will study. Italian language is ranked nearly at the end of the selections. Actually, from the surveys we have done with freshmen of Italian language on why they chose this language, it results that:

- $\quad 75 \%$ of them chose Italian just to fulfil the number of preferred studies and they attended because the Ministry of Education defined it based on their points

- $\quad 5.5 \%$ of them, because they like Italian language and have a fair knowledge of it

- $\quad 3.5 \%$ of them, because they want to attend master studies in Italy

- $3 \%$ of them, because they like Italy and what it represents

- 2.5 of them, because they have attended the bilingual lyceum, where Italian has been their primary language

- $1.5 \%$ of them do not know why.

- $\quad 0,5 \%$ of them, because they want to find a job in Italy.

Definitely, this shows clearly the lack of motivation our students have. Also, the fact that the selected field is ranked at the end, means that these students have fewer points, and as a consequence, it means that the level of students is not good, and if we take into consideration their lack of motivation, we can imagine that their future education in the application of this language will be poor and shallow. Therefore, even if they graduate, are they going to be able to use Italian with the quality the existing labour market demands? 
The Faculty of Foreign Languages, especially the Department of Italian language, actually offers three study cycles ( F.GJ.H, 2014), based on the Bologna Card System:

\section{- The first three-year Bachelor cycle in three profiles:}

a) Italian Language, Literature and Civilization, where the below subjects are taught in Italian language $\mathrm{GjB}$, while part of the subjects are done in Albanian language GjA (Albanian language and syntax) or Gjh C and Gj D:

$>$ First year: Practical Language (it), Phonetics (it), Introduction to Linguistics (it), Text Typology 1 (it).

$>$ Second year: Theory of literature (it), Italian Language Morphology, Text Typology 2/3 (it), Medieval / Modern / Contemporary History (it), Italian Literature 1/2, Italian Syntax, Stylistics (it), Lexicology (it), Research Methodology (it), Sociolinguistics (it)

$>$ Third year: Italian civilisation, Glottodidactics (it), Italian Literature 3/4, Text Typology 4, Text linguistics (it), Translation (it), Didactics (it), Language History (it), Philology (it), Introduction to Communication theory (it). Thesis (it)

b) Language and communication, first and second year coincide with the profile of Italian Language, Literature and Civilisation, whereas distinct changes in this profile are noticed in the third year,

$>\quad$ Third year: Italian civilisation 1/2, Introduction to Semiology (it), Basis of Anthropology (it), Italian Literature 3/4, Text Typology 4, Introduction to pragmatics, Text linguistics (it), Translation (it), Didactics (it), Language history(it), Philology (it), Introduction to Communication Theory (it). Thesis (it)

c) Translation and Interpretation, first and second year coincide with the above-mentioned profiles, whereas distinct changes in this profile are noticed in the third year,

$>$ Third year: Theory of Translation (it), Consecutive Interpretation ( $A-B, B-A)$, Text Typology 4 (it), Practice of Translation (A-B, B-A) 1/2, Simultaneous Translation, Comparison of Translation, Thesis (it)

\section{- Second two-year cycle, Scientific Master, which profiles in:}

a) Teaching-as follows:

First year: Teaching Methods and Critical Thinking (Alb), Development Psychology (Alb), Curriculum Development (Alb), Psycholinguistics and Foreign Language Methodology (It), Foreign Language, Learning and Class Management (Alb), Evaluation (Alb), Applied Linguistics and Intercultural Communication (it), Sources of Information for Teaching a Foreign Language (it)

$>$ Second year: Foreign Language for specific Purposes (it), Methodology of Scientific Research and Research in the Pedagogic Context of Foreign Language (it), Practical Laboratory for writing the final exam thesis (it). Practice. Thesis (it).

b) Intercultural and tourist communication

First year: Literature Culture B (it), Applied economics (alb), Tourist communication (it), Translation, Interpretation, Literature Culture A (alb), Public relations (alb), Literature Culture C.

$>$ Second year: Communication strategy (it), Archaeology and Ethnography / tourist enterprise (it), Methodology of scientific research (it), Translation (C-A), Practice, Thesis (it)

c) Translation

$>$ First year: Translation, Translation methodology and didactics, foreign language $\mathrm{C}$, Interpretation, Terminology translation, Translation C-A, and a subject of choice

> Second year: Translation C-A, Methodology of scientific research, Interpretation, Practice, Thesis (it).

- Third cycle, Doctorate School which has the below profiles:

$>$ Linguistics

$>$ Didactics and methods

$>$ Literature 


\section{$>$ Communication \\ $>$ History and civilisation}

We will deal more with the presentation of subjects that are done during only the first two study cycles, as they include nearly $98 \%$ of the students in our faculty.

The first three-year Bachelor cycle aims at a general education of the students with regards to the language, the country of origin with whom it is closely related. These three years serve to make the student understand what he is capable of, for a further profiling and what will be his specialty in the second and third study cycle.

But, analysing the curriculum and based on the continuous feedback from our students, we verify that besides the above-mentioned gaps, the stated subjects are in need of a review with regards to the improvement of, first, learning the Italian language as a communication language in every form, and then, in deepening other aspects related to it.

- What does this mean?

Our students face difficulties in learning the language, especially that of university. Despite the fact that they spend 160 hours learning the language, that is 6 hours/week for 30 weeks during the first year, for the majority of them the level of language remains in mediocre levels. Without any doubts, this brings frustration, emotional and affective barriers, and as a consequence, lack of motivation and no knowledge. This is later accompanied by incapability of understanding theoretical subjects and consequently, leads to low levels of education.

- What can be done?

Of course, there is area for improving the subjects and also the content of specific subjects in order to improve the situation. We have to admit that the blame is ours first, and then we can blame the student. We need to check where our gaps lie and not take for granted the fact that the students must know the language, because we know it. What we can suggest with regards to this issue is:

- $\quad$ Review of content and number of hours in subjects that deal specifically with language learning, such as: practical language, morphology, syntax and lexicology and the way they are presented, in order to make possible an effective and productive language learning for the student, making it possible for them to absorb enough knowledge that will enable them to deepen the learning of this language with the necessary will and passion to achieve a complete education that will serve in the future.

Also, in subjects of choice, students are offered subjects in the Albanian language, such as: Physical training, Human geography, Albanian literature, Economics, International relations, etc. It seems inappropriate for a foreign language student to participate in subjects that are not related to his profile, and especially in Albanian, with no aim to damage the general education of the student, who manages a complete background from high school, or to deteriorate the use of Albanian language. If Albanian subjects have to be organized, let's increase the hours in Albanian morphology and syntax which are reduced in a semester, while our specifics require from the student to be a good acknowledger of his native language first, and then of a foreign one. And actually, our students lack even in this aspect, which is important in knowing and then approaching two languages.

How can a student learn a foreign language when the reference points in the native language are weak and lacking? Even this is an issue that needs to be solved, but actually this needs to find a solution in the high school system, so that when the student studies at the university, he will not have to start learning the native language from the beginning. He must deepen and develop his critical, analytical, and approaching aspect in the university. This needs to be solved.

What can we do? We provided a solution previously: increase the number of hours in the classes of Albanian morphology and syntax. Another suggestion would be to include new subjects that aim at the improvement and development of writing in Albanian and acknowledging different typologies of Albanian text.

The second cycle aims at a true specific acknowledgment, specialization in the respective profile. But if we could look more carefully, we could see that there are issues, such as:

- In the teaching profile, the majority of the subjects are done in Albanian, especially during the first year, which is normally reflected in the linguistic education of the student, who stops at the effective use of the respective foreign language he is studying, despite the fact that the content and the teaching of these subjects are good ones, as they are prepared and taught from specialists, who have few or no knowledge of the Italian language. Still, this does not deny the fact that teaching Albanian from professors of Social Sciences represents a weakness for the Faculty of Foreign Languages. And this is verified not only from us, but also from the students themselves, who often complain on the lack of usage of Italian or for a seldom use in subjects which occupy less hours that the Albanian subjects. 
- $\quad$ Another fact that can be verified is that the teaching plans between the three profiles do not respect a fair share of subjects. Hours and credits are the same, but there is noticed that, while the teaching profile has a great number of subjects, the profile of communication and translation has a decreasing trend.

- $\quad$ Also, in the approach between the two cycles, there are noticed repetitions of subject titles. It is clear that the subjects are aligned to a deepening from one cycle to the other, but there should definitely be a specification to distinguish one module from the other.

However, we should accept the fact that these teaching plans are continuously improving, due to the fact that the Bologna process has been recently implemented and, of course, there will be issues and difficulties during the road, and it is important to identify and work for their improvement.

Still, we should accept the real fact that even with five long years of study, the Italian language students do not find a job in the majority of the cases, or, as we mentioned above, they find a job that has no relation to their education. This arises some questions that require an answer, as our students' development and the development of our department, as well, depends on them.

1. Has the labour market ever been tested in order to verify the specific needs it represents with regards to the usage of Italian language in terms of employment?

2. How many Italian language students have been employed in their specific profile after graduating?

3. Are our students capable to face the requirements of this market?

4. How valuable and practical has been the knowledge acquired during the study years in the workplace?

5. Is it necessary to review the curriculum of both study cycles, in order to approach more closely to the market requirements and students' needs for the future?

6. What proposals and suggestions can we offer in order to solve these issues?

Of course, before we start thinking about changing the curriculum and bringing forth other proposals and suggestions from other departments, it is necessary to carry on a more general research, in order to understand what truly is needed in the actual labour market, and not make assumptions based on those design curriculum, subjects and programs, which will not serve to the real employment of students in the future.

If we can make an overview of the Italian presence in Albania, we could verify a large number of investments, enterprises, schools, hospitals, medical labs, institutions: the embassy, the Italian Institute of Culture, The Italian Chamber of Commerce, which, as we explained previously, comes as a result of bilateral relations between our countries, which have been in place for a very long time. All these close collaborative relations in different areas and sections not only of economic, industrial, social and cultural nature, but of political, military and juridical, as well, are a very important indicator that there really exists the need for people with good knowledge and use of the Italian language. Let's take a closer look in the areas where the need is stronger and what their nature is.

With reference to data provided from different sources on the Italian presence in Albania, there is noticed that (ICE, 2013):

* Import from Italy: food, beverage, minerals, fuel, energy, chemical and plastic products, leather and similar products, wood and paper products, textile and shoes, building materials and metals, machinery, tools and exchange parts, etc., make a total of 1.211 million Euro $=32 \%$ of Albanian import

* Export to Italy: 748 million Euro $=51 \%$ of Albanian export.

* Italian and Italian-Albanian enterprises - 1460 active enterprises with different nature and forms, starting from commerce, light and heavy industry, telecommunication, agriculture, livestock, education, medical services, banking, television, etc.

Therefore, we can say that there are job positions in every area; it is only needed to find and apply. But that is not so simple:

The fact that the majority of employees in key positions or the respective administration of these enterprises is Italian and only simple employees are Albanian, because they are paid less than what is paid in Italy.

- $\quad$ What Italian entrepreneurs present as an issue is the fact that, if they accept employing Italian graduates, only a few of them possess enough knowledge of the Italian language needed for a specific position or a few of them are able to use it properly.

So, what is required from us is not only the creation of professionals with linguistics capability, but also to know what kind of professionals we need to form. Therefore, the labour market requires specifics, such as: language users with good knowledge in the economic \& industrial, health, administrative, communication and education section. Therefore, the purpose of our job is not to create invalid, theoretical and impractical education, but to make it practical and vital, so that it can serve to our students to achieve what they aspire in the future. 
Due to all the above-mentioned reasons, the purpose of this research is to identify what we need to do to change the actual reality.

The required intervention must be deep, vertical, as well as horizontal. What we can do is face the need of the market, so that our students will not be employed in positions that do not justify five years of study.

That's why, our faculty, and more concretely, our department, besides the review of the existing curriculum of the Italian language, has proposed the opening of professional short-term master studies, whose purpose will be the creation and forming of new professionals that will adapt to the labour market specifics. These proposals, designed from workgroups in our department, are linked to different areas, such as communication, knowing and using Italian for specific reasons, creating multimedia translators. They are presented below:

a) Professional master in translation - profile audio-visual, with the objective of : Preparing qualified professionals in the translation of audio-visual texts.

$>$ Subjects: History and theory of audio-visual translation, cinema and translation, theory of translation, characteristics of the audio-visual language, subtitles' translation, translation via dubbing, translation of cartoons, $C$ language translation, translation for dubbing language $C$, Practice, Thesis.

\section{Possible employment areas}

\section{$\checkmark$ Televisions}

$\checkmark \quad$ Different agencies that deal with translation and movie dubbing

b) Professional master in translation - technical profile, with the objective of: Preparing translators for different specific areas.

$>$ Subjects: Theory of specialized translation, Terminological aspects of specialized translation, Text editing, Linguistic and informatics sources of specialized translation, Characteristics of terminology and translation of economic texts, Characteristics of terminology and translation of medical texts, Characteristics of terminology and translation of administrative texts (language C),

\section{Possible employment areas}

Characteristics of terminology and translation of economic texts (language $\mathrm{C}$ ), Practice, Thesis.

$\checkmark$ Freelance translators

$\checkmark$ Employed translators (in translation societies, enterprises, organs, institutions of public and private research, national and international organizations)

$\checkmark \quad$ Translators in press offices

$\checkmark \quad$ Translators and linguistics consultants for information portals

c) Professional master in Communication - operative profile with the objective of: forming a professional general image with regards to the public relation area. It aims at enabling the student to intermediate and facilitate the communication between different institutions, between public and private institutions, between institutions and the public or even within the institution he is employed.

$>$ Subjects: Ethnology of public speech, institutional communication, public speaking, research and analysis of the material used in public communication, organizing and promoting public events, communication through art: music, cinema, pictures, techniques and strategies of online communication (language and culture $\mathrm{C}$ ), practice, and thesis.

\section{Possible employment areas}

$\checkmark \quad$ In different public or private institutions, as spokesperson in the public relation section

$\checkmark$ As a translator in the public relation section

$\checkmark \quad$ In the administration

$\checkmark \quad$ In different NGOS

$\checkmark \quad$ In newsroom

$\checkmark \quad$ Any kind of administrative assistance

$\checkmark \quad$ Any other institution that deals with public information

As we have noticed, the offered proposals highlight the preparation and formation of professionals in different areas in the use of Italian language, with the sole purpose of enabling our students not only to compete, but also aim a qualitative and adequate employment, which gives them the opportunity for a further development in their career and their future in the respective specific areas of their professional education. 
We do not pretend that, through these proposals, we are going to solve everything at once, which cannot be reached, because, in order to achieve this, there is required for both educational policies to play their role in the enforcement and preservation of the Italian language and culture. Also, with regards to the employment policies, it is essential to design and implement the agreement with effective Italian and Italian-Albanian enterprises which are present in Albania, with the purpose of mandatory employment of Albanian professionals.

Besides this, as the institution which prepares these generations of students, we think that it would be very effective if a common agenda should be prepared together with the private Italian enterprises of every sector that are operating in Albania. Such a step would require preliminary meetings in the beginning of the academic year with representatives of such enterprises, where they would present real needs they have for students with the appropriate profile for such job positions. Such a structured and long term (3-5 year) agenda would highlight the areas of improvement in the existing curricula or even introducing new elements in the existing ones. But, normally, this would be most effective in the labour market. In the light of such an organization, we have to add that we need to thoroughly consult the legislation with regards to the design of a common agreement with these foreign private sectors operating in the Albanian territory. This legal "precaution" would avoid any kind of future dissatisfaction or disagreements from both parts.

There is still a lot to be done and more difficult challenges await us in the future, but we will try hard to make it possible for our students to gain enough knowledge and make them ready to handle with success the challenges they will face after graduation.

\section{Bibliography}

Balboni, E. P., (1994), Didattica dellitaliano a stranieri, Bonacci editore, Roma, pg 20.

F.GJ. H - Dokumentacioni i Fakultetit të gjuhëve të huaja, Tiranë

Ministria e Arsimit dhe Shkencës - Zyra e statistikave 2013.

Ambasada italiane - http://www.ambtirana.esteri.it/Ambasciata_Tirana/Menu/l_rapporti_bilaterali/Cooperazione+culturale/, 16.03.2014

ISTAT- 100 statistiche per capire il paese in cui viviamo http://culturaincifre.istat.it/sito/in_evidenza/Noi_Italia_2012.

ICE- http://www.ice.gov.it/paesi/europa/albania/index.htm, 14.03.2014

Husha A., (2013) - L'itegrazione degli albanesi in Italia. Dati statistici. http://www.albiptariiitalise.com/component/content/article/35-tejetosh-ne-itali/4106-lintegrazione-degli-albanesi-in-italia.html, 13.03.2014 